\title{
THE CULTURAL ACTIVITIES CLUSTER IN PORTUGAL Trends and perspectives
}

\author{
Pedro Costa
}

\begin{abstract}
The aim of this article is to evaluate briefly the importance of cultural activities in the Portuguese economy, identifying the main trends and opportunities for this cluster in today's world. The concept of "cultural industries" is discussed and the role of the cluster in the Portuguese economy and society is analysed, on the basis of empirical information, both statistical and qualitative. The territorial dimension of the organization of the cluster is strongly emphasized, with a comparative regional perspective being used to study the provision and consumption of these goods. Also explored is the relationship between the economic, cultural and institutional processes that are beyond the provision of these activities, and which are central to their comprehension.
\end{abstract}

Keywords Cultural activities, Portugal, territory, culture.

\section{Introduction: cultural activities, territorial competitiveness and development}

The main goal of this text is to assess the importance of cultural activities in the Portuguese economy, identifying the main trends and opportunities for this cluster in today's world. ${ }^{1}$ This reflection is made with a broader perspective, which concerns the role of cultural activities in promoting the development and competitiveness of different territories. ${ }^{2}$

As a working basis, given the increasing crossovers between different forms of cultural activities, we start with a broader conception of cultural activities. This includes all forms of what is traditionally understood as art and popular culture. We tryto avoid dichotomous and simplistic distinctions, such as those that traditionally make a distinction between "high culture" and "mass culture", between art and industry, between live and unique performances and reproducible goods, between commercial and non-commercial consumption and provision of cultural products, and between public or market providers (see Costa, 1998; Wynne, 1992). From the conventional "cultural industries" (such as books or records) to the media, the cinema, the visual arts, the performing arts, heritage conservation, or handcrafts, for example, these activities, in all their diversity, are, essentially, activities that use artistic and creative inputs. They have, moreover, the prime objective of expressing information and creating meanings (Montgomery, 1994), whether it is inside relatively autonomous and internally coherent sectors or sub-clusters (like the record or book industry, or the audiovisual, for example), or it feeds a vast 
range of other economic sectors (like advertising, design, fashion or architecture, for example).

Thus, independently of the multiplicity of goods and services that result from all these activities (which are characterized, as is noted by Lash and Urry, 1994 and Scott, 1996, by a higher level of aesthetic and semiotic attributes), and given the fact that these cultural products (as they are named by Scott), consequently, assume the most heterogeneous forms, our analysis is centred on the central part of these activities (and its range is not so broad as the concepts of anthropology or cultural studies). They include all the things that are usually associated with artistic creation and the various forms of popular culture. Our cultural activities cluster, hence, aggregates the multiplicity of practices and activities included in this concept (and should be analysed with an economic filière logic in mind), which we will divide, as seen later in this article, into four main sub-groups of activities, for analytical purposes (see also Costa, 1999a).

Cultural activities, like any other economic and social activities, can be boosted to promote territorial competitiveness and development. This is not the place to debate the notion of territorial competitiveness, a complex and controversial concept that has been and will be discussed on other occasions (e.g. Costa, 1999b). On this question, for the moment, we only want to state two supporting ideas that appear between the lines of all our latest thought.

In the first place, the notion that our concept of competitiveness goes beyond (but neither excludes nor dispenses with) simple economic competitiveness (and, obviously, exceeds the simple logic of profitability).

It relates to the possibility of each territory acceding to sustainable development, in its many dimensions, from the promotion of economic efficiency to the preservation of environmental quality and natural resources, from a preoccupation with social equity to a guarantee of the right to participate and to assume and exercise citizenship to its full extent (see, for example, Costa, 1999b; Costa and Rato, 1999).

In this context, cultural activities should be seen not only as a means to promote development, in these different dimensions (because they create jobs and economic value and allow the rehabilitation of the urban spaces, the participation and self-expression of the population and the integration of excluded social segments). They should equally be seen as a final dimension in the processes of development (because they offer the chance of promoting the quality of life and well-being, by allowing the affirmation of territorial specificities and identities, preserving the collective memory, and being a vehicle for creative expression).

A second preliminary idea that we would like to focus on is that in the context of globalisation, it is currently recognized that the paradigm of territorial competitiveness depends on the capacity that each space has to offer specificity, to give value to its assets, in global economic and social circumstances. This obviously does not mean a tendency towards autarchy, but, on the contrary, strongly stimulates the search for the external upward revaluation of endogenous factors that can support a positive insertion in this wider reality. 
In this situation, cultural activities can have a decisive role in territorial competitiveness, and this for two sets of circumstances.

On the one hand, because of the growth of the importance of these activities in contemporary economies. Despite all the diversity of these activities, ${ }^{3}$ their growth in the societies and economies of the most developed countries is clear and secure. It can be estimated (with extremely variable criteria) that it already represents between $2 \%$ and $5 \%$ of the added value and the employment created in these economies (v. EC, 1998; Benhamou, 1996; Montgomery, 1994; Costa, 1999a). Its importance in the promotion of competitiveness will then be crucial, when these activities cumulatively, as said above, allow several of the essential dimensions for sustainable development to be brought together. ${ }^{4}$

On the other hand, because these activities have a "cultural" content (using the wider concept of the term) that can make a huge difference in spacial terms, and are thus activities that can be extremely valuable as a competitive advantage for each specific territory. In addition, the cultural (symbolic, aesthetic, etc.) content of goods (even the most traditional material goods: clothes, construction, furniture, etc.) has been strongly emphasized by some authors (e.g., Scott, 1996; Lash and Urry, 1994), as a way of affirming territorial competitiveness.

However, cultural activities are extremely heterogeneous, at all the different levels (the organization of production, the scope of consumer patterns, employment links, market structures, the commodity level of the offered goods, etc.), and cannot all be analysed in the same way. Regarding our main interest — their relationship with space — we can mark them into four big categories (Costa, 1999b): ${ }^{5}$

a) The "core" of cultural industries (the audiovisual media and cinema; the publishing and recording industries; and increasingly, everything that borders on communication, the media, information technology, and the entertainment and leisure industries in general). The provision of these goods is centred on the logic of the market, and is based, in specific sub-filières and process stages, on the logic of functioning on a world scale (for example, the movies or record distribution, videogames or computer software). Concerning their relation with territory, three stages clearly take shape in the value chains associated with the provision of these goods:

- a first stage, related to the artistic creation and the production of the good or cultural service, which, in spatial terms, frequently demands the agglomeration of the agents, due to the external economies generated by their concentration and the formal and non-formal inter-relations established between them (which can provoke the outcome of a dynamic nucleus, territorially very marked, for certain activities);

- a second stage, attached to the diffusion and distribution of those goods, which seems to appear progressively de-territorialized (even totally globalized, for some products), due to technological progress and the advance of the globalisation process.

- and a third stage, based on the reception of goods, that is to say, on the cultural practices (endo- or exo-domiciliary), which territorial distribution clearly 
changes with the very different segmentation of the practices and with the critical demand thresholds that exist for supplying those goods.

According to this logic, certain activities (particularly the more extensive mass practices) will be progressively expanded to wider spaces, while others, mainly in the fields of creation and production (where the agglomeration economies and the milieu effect have a significant weight) and of more specialized consumption (with demand thresholds that are restricted and spatially concentrated), will continue to be concentrated at specific points. That leads us to a straight relationship with the urban hierarchy, ${ }^{6}$ and also to the importance of territoriality, allowing a boost in activities (more or less specialized) where there will be competitive advantages in their provision or consumption (Costa, 1998; 1999b). The logic of the international / national / regional division of labour is clearly visible in these activities, as the various spaces seek a position that will allow them to be efficiently and competitively inserted in the value chain of each good (from conception to the last element of distribution).

b) "Cultivated", "institutional", "legitimated" culture: these activities, generally associated with "erudite" or "high" culture (a large part of the performing arts - mainly in the fields of opera, dance, classical music and theatre - and visual arts - big museums and galleries, etc.), are related to the central nucleon of traditional and conventional cultural politics. They are provided from different sources, but due to their economic characteristics, are generally subsidized (by the public authorities, but not only - the Sponsorship Act is an example.). Due to the great demands on resources, to the fact that they are set in motion (in private and public institutions) at centralized levels of decision, and to the spatial agglomeration of their audiences, these activities tend to be concentrated in the larger urban centres. This is despite the fact that in recent years the different policies of cultural decentralization, in various countries (including Portugal) have led to some positive effects. The strong "institutional" weight and the elevated costs of providing this kind of culture are factors that, in general, have reinforced the asymmetries in its territorial distribution.

c) Popular culture, based on urban forms of sociability: these activities are playing a growing role in today's societies and are assuming a decisive position in restructuring many spaces in numerous urban centres in the most-developed countries. There are various activities, mainly related to some expression of popular culture, but also to minorities and independent fringes of the culture industries, as well as to some more marginal and creative movements within the legitimated "high culture". In these cases we can find multiple activities in the field of popular music, dance, theatre, cinema, video and multimedia, plastic arts, design, fashion, and information technologies, among others. Besides the strong concentration in socio-economic, and, mainly, specific age-group strata (at least some of them can be placed in what $\mathrm{O}^{\prime} \mathrm{Connor}$ and Wynne, 1996, call the youth cultural industries) and an attachment to cultural 
and social models of their own, ${ }^{7}$ they have in common the fact that this culture's development is generally related to a strong territoriality. ${ }^{8}$

d) Preserving and increasing the worth of a particular cultural heritage and identity (all "saved" memory - writing, images, sounds —, monuments, buildings, ruins, ancestral traditions, handicrafts, gastronomy and so on). It is natural that these activities have a direct relationship with the land, so the trademark of specificity (sometimes translated into a trademark of territorial marketing) can be given enhanced value, specifically and differentially, by each space, so that it can promote its identity and preserve/secure its own culture internally and externally, which is, in other words, to develop...

These four big groups of activities represent a sufficient body of distinct realities (in economic, social and institutional terms) to justify, for each of them, thinking of the relationship with the territory in a different form. Nevertheless, in all of them the question of territoriality is, as seen, crucial. Be it in the possibility of each space to adapt to a globalized value chain of the production of a generalist product of one of the most well-structured cultural industries, or in the combination of the interrelations that foster creativity or entrepreneurship and are at the foot of the rise of an innovative or extremely specialized product, or be it in the possibility of each space to preserve and raise the perceived value of its collective cultural memory; among many other examples, the space itself assumes an important role in the outcome and development of all these activities, when they can be, simultaneously, an unquestionable source of competitive advantage for those territories.

However these four categories are not exclusive and show many aspects of interpenetration. For example, various activities in the sub-file of cinema or music can be seen in several of these categories, simultaneously: mass or independent production in structured files, small niche markets of production or exhibition associated with specific territorial realities, the preservation of the memory of that art, etc. They not only allow us to categorize distinct ways of identifying with territories, but, even more, give us the chance to reflect in a clearer way about the definition of strategic policies, based on transversal areas of action.

This reflection can be extremely important at the level of political action in the situation, since the dynamism of these cultural activities, independently of their nature, is essentially related to the involvement of the various agents (with their motivation, expectations and specific conditioning) in concrete projects and practices, which must be based on the assets available in that territory.

\section{The cultural activities in Portugal: some recent trends}

With this framework in mind, we shall now centre our attention on an analysis of recent developments in these activities in present-day Portugal. 
The results we briefly present next are part of those we are producing in our wider investigation of cultural activities in Portugal and their relationship with space. In spite of the vast amount of empirical information we are using (both statistical and qualitative, from many sources, from institutional agents to public authorities and creators), we have opted in this paper to present only certain topics, which allow us to outline the main trends.

So, for each of our four cultural activities categories, in the following items we shall try to schematise the main trends we identify in relation to the provision and consumption of cultural goods, the cultural policies implemented and the perspectives for each of them, with particular attention to the territorial dynamics that underlieand are deeply interrelated with them.

Let us look closely at each of these parts of the cultural activities cluster, trying to identify the mechanisms behind their existence, so that we can then reflect more consistently on their development prospects in our country.

\section{The core of cultural industries}

In common with global trends, cultural industries in Portugal are passing through profound structural transformations. The trends to technological convergence, revolutionizing the conventional sub-sectors (cinema, audiovisual media, publishing, music, video, information technology, equipment production, etc.) are particularly evident, and we are facing a value chain in accelerated mutation and imbrications. Cultural contents mostly appear gradually in a great variety of windows (books, magazines, the Internet, compact disks, magnetic format, TV clips, public exhibition spaces, etc), progressively integrated (e.g. cinema, music, advertising, information, videogames and even clothing can sell - and be sold - with the same characters).

The predictable digitalisation, covering most of the production, copying, transaction and broadcasting of all cultural contents, will co-exist with fringes to traditional formats (cinema, books, newspapers, etc. - most of them very dynamic nowadays), which may rest on different competitive factors than nowadays. It will revolutionize and interact with the equipment, support, and hardware infrastructure industries (with minor importance in our country).

In parallel with this, it is possible to see various movements of (vertical and horizontal) economic concentration, inserted in or reacting to the same movements at global level (in the audiovisual sector, in multimedia groups, linking with telecommunications and information technology firms, or even in other sectors - entertainment, travel, finance, etc.). The main markets (cinema, music, video, for instance) are generally fully integrated in global processes (in spite of some growing reaction, at supply and demand levels), while other ones are to a lesser extent (publishing, media, etc.). Nevertheless, the trend to economic concentration among those markets in Portugal is evident, with the consolidation of big multimedia groups (mostly private, but some with public participation), and with the increasing integration of audiovisual technology, the media, information, 
telecommunications and information technologies. This concentration of capital is territorially concentrated in the main places of decision-making and power, particularly the Lisbon Metropolitan Area.

The trend to globalisation and standardization (particularly notable, when compared with other European countries, in the fields of the audiovisual media and music) leads, in an apparently paradoxical way, to the growth of various market niches, exploiting the diversification of their markets, which can be differentially exploited by the diverse territories (mainly in the big cities, but gradually in a number of other towns, as their supporters increase, and the critical supply thresholds are crossed).

Public intervention in this area has developed in two ways (also marked by the political changes, from more liberal PSD governments (from 1985 to 1995) to more interventionist PS ones (from 1995 until now). It has been more interventionist in some areas (public support for the cinema, fixed book prices, for instance); and less in others, with a gradual privatisation of processes for cultural provision (e.g. the Sponsorship Act), but most of all in the establishment of private radio and television stations (and later, in the convergence between economic groups related to the media, telecommunications and information technology). In market terms, there is an increase in the demand (trends to an expansion in schooling and purchasing capacity, mainly among the younger classes, who are the principal consumers), with the usual strong segmentations (cf. Pais, 1994). The most popular are endo-domiciliary, though with a significant increase, in recent years, with respect to the cinema, the main exo-domiciliary cultural practice.

There is clear market segmentation, with an increasing number of independent markets, particularly in bigger cities. As is natural, mass products and services are territorially more widespread, while more specific ones are concentrated in large areas (and, on a smaller scale, some of them in medium-sized cities, particularly those with a young student population, namely the ones with a university life).

There have been several transformations in distribution circuits (with the spread of the sale of books, videos and records in hypermarkets, the decrease in small retail-trading, the shopping-centre boom, the entry of international mega stores and cultural sales organizations, the increase in specialized stores, including specialist second-hand stores, e-commerce, and so on), reflecting wider transformations in Portuguese commerce. These transformations have had strong territorial impacts (with a concentration of specialized supply in the centres of metropolitan areas or big cities, and the progressive spread of the sale of what are, to a greater or lesser extent, mass goods to the periphery of these areas and to smaller towns).

In some activities (particularly in the fields of music, books or the cinema), the growth of the markets has led to changes in the suppliers, with the entry of independent editors and producers to these markets, offering more creative, artistic or specific products (or processes) and being more concerned with the value of creativity and differentiation. In some markets (like music or cinema), the turning of traditional editors and producers' attention to a more "commercial", standardized and globalized pattern (for instance, trying to produce in Portugal some kinds of 
goods that were traditionally imported - e.g. American mainstream cinema or certain Anglo-saxon musical phenomena) has created difficulties for the support given to more independent talent (which, gradually, has arranged more auto-production facilities, and has seen some rise in public support for the arts ).

In spite of the central place of the market and private initiatives in these cultural ind ustries (even for the more independent aesthetic options, mainly in branches like the cinema, book publishing and the recordingindustry), there is strong support from the state for some of these activities, as we have seen (book prices, support for creating, exhibiting, and publishing), directed mainly at independent production (besides, of course, the public position in the media), and there is a tendency towards partnerships among diverse actors (e.g., multimedia; cinema and audiovisual production, publication of our musical heritage).

Although the localization of these activities (mainly in the production phase) is specially concentrated (in Lisbon, and, to a lesser extent, in Oporto), there are occasional initiatives in many towns, (photo and image encounters, cinema festivals, and pop, rock, jazz or classical music festivals) which have considerable importance for their territorial assertion. The equipment and support industry is one of the few exceptions to this territorial centralization, with some weight in the northern industrial region.

Finally, it may be noted that some of the questions under discussion in international forums (WTO agreements or copyright laws, for instance), have an enormous relevance for the organization of this sector (and territorial implantation).

\section{"Cultivated", "legitimated" and "institutional" culture}

These activities make, even nowadays, the greatest symbolic mark as cultural activities, particularly among certain social strata, public decision-makers (at national level) and big firms (the source of a great part of the sponsorship of these activities, regarded as a more secure investment).

The market has in general developed positively, and has grown mostly on the basis of diversification on the supply side, not only by public providers but also by foundations or even supported groups or associations.

There was a certain re-allocation of public responsibilities (mainly until 1995) with the Sponsorship Act and the creation of state-sponsored foundations (S. Carlos and Descobertas - to be discussed later), but cultural production in this field continues to be highly dependent on public (central) subsidies.

Besides big national (public and other) structures, there is significant support (direct and indirect) from central authorities for those arts, by sector-specific institutes (IPAE, for performing arts, IAC for visual arts, and so on), not only on the side of creativity, but also for artists and projects.

Nevertheless, the Sponsorship Act (Lei do Mecenato), many times discussed and reformulated, plays a significant role in some of this production, involving some big firms in the financing of these activities.

These activities, more than any others, are traditionally characterized by their 
great territorial concentration and central dependency, due to the high costs of providing them and their institutional characteristics (opera, national theatre, dance, classical music, etc.). Portugal is no exception, with its centralized and concentrated structures (national companies for dance, theatre, opera, etc.), and sector-specific national institutes (for performing arts, for visual arts, and so on).

We can, however, notice a certain "deconcentration", mainly from national public authorities to a number of foundations (with several formats: private, public, mixed) which play a fundamental role in making culture available in the biggest cities (the Fundação Calouste Gulbenkian (since the 1960s, in Lisbon), the Fundação de Serralves (in Oporto), the Fundação das Descobertas and the Fundação S. Carlos (with national public structures), Culturgest (associated with a financial group), the Fundação Arpad - Vieira da Silva, the Fundação Berardo, etc.).

There is also a tendency for territorial decentralization, with some interesting results, set in motion mainly by central authorities (touring programs (Programa Rotas), the recuperation of auditoriums in small and medium-sized cities (Cine-Teatros), and the localization of public institutes (e.g. Centro Português de Fotografia in Oporto)).

But these activities are mainly concentrated in big cities, particularly Lisbon (at least, for events with international impact), as in most European countries.

With regard to these activities, there is also the importance of equipment recovering and maintenance, which in some institutions conflicts, for financial reasons, with support for events and artistic creativity.

Occasional initiatives from private agents or local authorities, with some support at national level, are noted, mainly in the visual arts (art galleries) and certain areas of the performing arts (mainly theatre, music and dance in some cities). The growth in responsibilities and funds assigned to local authorities has been crucial for this point.

\section{Popular culture, based on urban forms of sociability}

As in other European countries, and also as part of the globalisation process, there is an accentuated growth in these activities, mainly in metropolitan areas (but, generally, in all towns), that is, in activities associated with the fields of popular music, dance, theatre, cinema, video and multimedia, the visual arts, design, fashion, and information technologies, among others.

These activities are essentially provided and consumed by young and (at least for some of them) scholarly segments of the population. Their expansion is related to changes in mentality, values, and expectations (greater value given to hedonism, socialising, etc.), associated with schooling, access to the media, and income modifications, all of which has de-mystified the conventional notions of "cultu$\mathrm{re}^{\prime \prime}$. An association with other activities (clubbing, fashion, etc.) is often apparent.

These activities are mainly related to some form of expression of popular culture, though also to minorities and independent creators and promoters from the mass-culture industries (music, cinema, video, literature, multimedia, among 
others) and to certain more marginal and creative movements inside the established "high culture" (alternative theatre, dance, music, etc.). They are, essentially, activities related to urban sociability.

They sometimes seem highly integrated in marked-out territorial situations (in territorial clusters of activities, like the Bairro Alto, in Lisbon, and, to a lesser extent, certain quarters in other cities), based on strong endogenous mechanisms (formal and informal networks, personal relationships, forms of sociability, etc.), and also in rich agglomeration economies and in an image that is, internally and externally, commonly perceived. Many of these activities are strongly linked to urban renewal operations (for instance, the recovery of the Tejo waterfront or the Parque das Nações in Lisbon; the Ribeira, in Oporto) but many of them are embedded in specific territorial dynamics (the Bairro Alto, for instance) or simply associated with the growth of leisure and entertainment and the different forms of street vibrancy (of private or public origin).

The progressive social institutionalisation of these forms of popular culture, facilitated by changes in school socialization and by the media, results in a multiplicity of forms of cultural expression (from discos and pubs to experimental video, from graffiti to fado and other traditional expressions of culture, and from fashion to second-hand record or book stores) developed by a multiplicity of agents (mainly associations or SME's) and institutional schemes.

Most of these activities, inspired by creative ambitions, originate in the entrepreneurship of voluntary cultural associations (which then evolve into SMEs) and independent promoters or artists, some without external financing. Many of them tend to be supported (at least, partially), by local and central public funds, sometimes evolving into other kinds of networks or different institutional solutions.

Public authority support (local and, mainly, central) for artistic creation is often crucial for the realization of these projects, with their experimental, artistic and creative characteristics (and, thus, a risk for sponsors, for example).

In spite of the concentration of these activities in some quarters of the biggest cities (mainly Lisbon and Oporto), growth of this kind of cultural activity can be seen in all medium and small-sized towns, particularly the centres with a university life.

Amateur cultural associations also play an important role, and one that is spread throughout the country. Local authorities play a key and increasing role in supporting cultural associations and local-culture activities. Volunteer associations make a significant contribution to local cultural life and, among a number of other promoters of initiatives, play a major role in arranging theatrical performances, book fairs, film shows and folklore.

The spread of partnerships and crossover co-operation, mainly between local authorities and associations, is common in the whole country, though mainly in the most populated areas of metropolitan regions. 


\section{Preserving and increasing the worth of a particular cultural heritage and identity}

A number of successive measures have been introduced since the creation of the Portuguese Cultural Heritage Institute in 1980 - organizational restructuring, establishment of a national network of archives and the creation of an inventory of the national heritage. Despite all this reorganization, heritage remains a field of overlapping and competing responsibilities.

There has been a rise in the number of listed buildings and museums open to the public, which have seen increased their numbers of visitors (particularly in the Lisbon area), but mainly, there has been significant growth in the social (and political) awareness of the value of the cultural heritage.

This social awareness (combined with a stronger bias to the concern with the economic worth of these activities) is intimately associated with the rise in tourist activity (historical, environmental, sport, heritage etc.), the increase in leisure time, and the increased interest in environmental values and the conservation of natural resources.

There was strong growth in expenditure on national heritage ( $144 \%$ between 1985 and 1995, Council of Europe, 2000), which reflects the significant role of public authorities (mainly at central level) in this area. But there are also many other institutions and projects in this field, assisted by private foundations or partnerships (e.g. Sintra Modern Art Museum, which is supported by the Berardo Foundation).

Simultaneously, there is an increasing role being played by local authorities (gradually, with greater competences, further sources of financing and more human capital), in various fields, from public libraries and other municipal archives (image, sound, etc.), to small museums, and from the conservation and recuperation of built or natural heritage to the preservation of ancestral traditions, folklore or gastronomy.

Many cities and places (Évora, Sintra, Porto and Angra do Heroísmo, among others) used their classification as World Heritage Sites (and other initiatives) to preserve, promote, differentiate and upgrade their specific assets, particularly in the fields of urban rehabilitation and tourism.

Another important dimension is related to the internationalisation of Portuguese (and sub-national) culture and languages. In this field, there are occasional operations in foreign countries (Europália-91, presence at international book or media fairs and World Exhibitions, etc.), and international forums (UNESCO, the Council of Europe and others). In addition, there are national institutions (Instituto Camões) or international ones (CPLP - the Community of Portuguese-Speaking Countries) that are involved with the Portuguese language and Portuguese relations with specific communities and countries, and with other diverse programmes, helping to spread the Portuguese language and Portuguese culture (establishment of cultural centres abroad and a network of assistants, radio and TV broadcasts, multimedia, etc.).

The integration of cultural minorities is being achieved gradually, without great difficulty, given that the social and cultural contrasts between the minorities and the majority of the population are not very significant, although they are rising 
(mainly on the periphery of metropolitan areas, particularly Lisbon, or in the more conservative north). Only recently have the political authorities turned their attention to questions associated with ethnic minorities in Portugal, adopting a more interventionist position.

These are the main trends that, at the present point of our investigation, have been identified for each of our four cultural activities sub-clusters. Nevertheless, there are transversal questions relating to all these activities, which we cannot underestimate.

One of them involves everything that is related to the education and training system. The preparation of the human resources that create, produce and consume cultural goods and services is one of the fundamental aspects we (and any specific territory) should take into account. The development of the activities in each of these four categories (and even their relative weights) is strongly determined by factors like the formation of audiences and tastes, artistic education (essential to creative expression) and technical training (in the use and development of equipments, hardware/software; and in the preparation of cultural mediators, for instance), or the endowment of entrepreneurial and management skills in these areas. This means that this is a crucial area for public intervention in any one of the four types of cultural activities.

A second question we would like to highlight refers to the importance of big events and projects, with their great mobilizing capacity. Events like the World Expo in Lisbon in 1998, the Cultural Capitals of Europe programme (Lisboa-94 and Porto 2001) and many different projects backed by central or local authorities in urban rehabilitation (historical and degraded districts and harbour areas) ${ }^{9}$ have been initiatives with some cultural impact (in general, in the four different categories of activity). Examples are the (most ephemeral) support for creation and production and the complementary dimension of the construction and modernization of equipment and infrastructure.

A third and last transversal question we would like to mention is related to this. It is the importance of the institutional fabric and of the interrelations among different actors, generating the most varied institutional solutions for specific purposes. The role of the motivation and expectations of the different agents (private entrepreneurs, artistic creators, audiences, central government authorities, local authorities, advertisers, educational and training centres, etc.) has a crucial importance, and (principally for some of the activities in the cluster) is the key to the generation of activities and projects (and supporters and values). Thus, the density of the institutional and relational fabric is a fundamental aspect that should be thought of by all territories in the promotion of their development and competitiveness.

Moreover, besides these three important questions, though it is transversal and related to all of them, there is another one we would like to bring up again, because it is the one that is central to our work: it is the permanent importance of spatial inscription to the development of these activities. Space is not neutral and territories (with their specific combination of agents, factors and institutional relations, and with their own culture and history) assume an essential role in the outcome 
and consolidation of these economic activities and social practices (in different ways, but in all four categories).

\section{Concluding note}

We have tried in this paper briefly to synthesize some preliminary conclusions from the empirical data we are examining on the importance of cultural activities in the Portuguese economy.

Although they have the character of preliminary results, their usefulness lies in the opportunity they offer to assess and understand the relationship between cultural activities and territorial development, and to provide an analytical scheme that is of value when action is to be taken in the territory to promote its competitiveness.

It is thus important to proceed to a more comprehensive study of these activities and the specific forms of interrelating among the agents, in concrete cases. That cannot take place without a concern for certain policy issues and debates: the question of the de-mystification of culture (with the assumption of the centrality of all cultural forms, even in policy making?), the question of the participation of private agents and the role of different kinds of actors in the cultural field (private-public relationships; modes of financing; strategic projects); the issue of the decentralization of cultural policies, with greater weight being given to local authorities, and mainly, to the participation of any other kind of agents in the most diverse kinds of partnership; the question of the tension between the support to the ephemeral (for creation, performances, happenings, and so on) vs. the construction of infrastructure (durable, and mostly, politically attractive); and so on, and so on.

These preliminary conclusions also allow us to emphasize the obvious importance of the cultural and institutional dimension (not only the economic) in the provision of these activities. That is the key for the policy action mentioned above. In the globalized world we live in, any specific territory must) maximise the value of its best assets to promote its competitiveness. If this is true for economic goods in general, it will be even more so for cultural goods with high aesthetic value and specific symbolic contents. Thus, the promotion, in any particular space, of competitiveness and development depends on a combination of economic, institutional, cultural and historical factors that are behind the provision and consumption of the goods, in this case, cultural products. The politicians and planners just have to find and promote, for each specific case, the best solution using the capacities and resources available. A strategic planning approach involving all the agents and respecting all the sensibilities at the different decision levels is then essential, to promote the great opportunities offered by this cluster in present-day Portugal. 


\section{Notes}

This text corresponds to the revised version of the presentation to the 10th Annual Conference of the European Research Network on Services and Space (RESER), which took place in Bergen, Norway, between $5^{\text {th }}$ and $6^{\text {th }}$ of October 2000, on the theme "Beyond the Economic? Institutional and Cultural Dimensions of Services". A previous version was produced as a working paper for Dinâmia in 2001. We would like to acknowledge the very significant commentaries of João Ferrão and Raul Lopes and the dedicated contribution of Hélia Costa and Paulo Pires in translation. This text is part of a wider investigation in progress, leading to a PhD thesis in Regional and Urban Planning, in which the relationship between cultural activities and territorial competitiveness is studied, based on the Lisbon Metropolitan Area. Our purpose here is not to present concrete, definitive and structured empirical information, but simply to seek to provide a preliminary schematic and synthetic approach to the main tendencies that can be outlined on the basis of our broader investigation process.

3 And they are effectively the most diverse, from the most structured cultural industries (cinema, records, books) to the performing arts, from the visual arts to fashion; from the cultural heritage to the new night-life (see, for example, Costa,1998,1999a).

4 In addition they are activities that assume a growing part of people's lives, due to structural changes of mentality, life style and values.

5 The construction of these four categories results not only from the relationship with territory, but also from wider objectives and criteria of the current investigation (forms of regulation, institutional organization, the structure and functioning of markets, sources of financing, types of provision, and consumption modes).

6 Not necessarily linear, with the possibility of undersized spaces achieving a competitive specialization in hierarchically elevated central functions.

7 Ways of life highly centred on the urban space and on culture and leisure, where the boundaries between work and leisure, between production and consumption, between creativity and appropriation are often laid down, and where mutual relationships, mingling and social life take a central place.

8 We had other opportunities (Costa 1999, 1999a) of associating this logic of functioning with that of the innovative milieus, and mainly of focusing the observation of these phenomena not only on strong globally competitive clusters (the cinema in Hollywood, fashion in Paris, etc.) but also on the cultural quarters in several cities (e.g. the Bairro Alto in Lisbon).

9 The next POLIS programme will be an excellent opportunity for this. 


\section{References}

Benhamou, F. (1996), L'économie de la Culture, Paris, Éditions La Découverte.

Bianchini, F., and M. Parkinson (eds.) (1993), Cultural Policy and Urban Regeneration, Manchester, Manchester University Press.

Castells, M. (1996), The Information Age: Economy, Society and Culture, in The Rise of the Network Society, Volume 1, Oxford, Blackwell.

CIMA (1997), Relatório da Comissão Inter-Ministerial para o Audiovisual, Comissão Inter-Ministerial para o Audiovisual (versão electrónica em http://www.min-cultura.pt/CIMA/hdr.html).

Conde, I. (1997), “Cenários de práticas culturais em Portugal (1979-1995)”, Sociologia, Problemas e Práticas, 23, pp. 117-188.

Costa, P. (1998), "A fileira das actividades culturais e a economia urbana”, comunicação ao 1ํㅡㄹ Congresso Português de Sociologia Económica, Lisboa, Fundação Calouste Gulbenkian, 4 a 6 de Março de 1998.

Costa, P. (1999a), “Efeito de 'meio' e desenvolvimento urbano: o caso da fileira da cultura", Sociologia, Problemas e Práticas, 29, pp 127-149.

Costa, P. (1999b), “Actividades culturais e desenvolvimento regional: novos caminhos para a competitividade territorial", Cidades e Regiões na União Europeia: Actas do VI Encontro Nacional, Coimbra, APDR.

Costa, P. (2000a), “Centros e margens: produção e práticas culturais na Área Metropolitana de Lisboa", Análise Social, xxxiv (154), pp 957-983.

Costa, P. (2000b), "Cultura e competitividade territorial: o caso do cinema português", comunicação ao IV Congresso Português de Sociologia, Coimbra, 17-19 Abril 2000.

Costa, P., and B. Rato (1999), "The audiovisual cluster in Portugal: which competitiveness in a globalized economy?", comunicação à IX Annual Conference of the European Research Network on Services and Space (RESER): Services on the Eve of the XXI Century: Growth, Globalisation and the EMU, Madrid, Alcalá de Henares, 7-8 Outubro 1999.

Council of Europe: ERICarts (1999), Cultural Policies in Europe: A Compendium of Basic Facts and Trends, Council of Europe, ERICarts.

Crane, D. (1992), The Production of Culture: Media and the Urban Arts, Newbury Park, Sage. EC (1998), Culture, the Cultural Industries and Employment, DG V / DG X, Commission staff working paper, (http://europa.eu.int/en/comm/dg10/culture /emploi-culture-intro_en.html)

Fortuna, C. (org.) (1997), Cidade, Cultura e Globalização: Ensaios de Sociologia, Oeiras, Celta Editora.

Lash, S. and J. Urry (1994), Economies of Signs and Spaces, London, Sage.

Lopes, J. T. (2000), A Cidade e Cultura: Um Estudo Sobre Práticas Culturais Urbanas, Porto, Afrontamento.

Montgomery, J. (1994), The Knowledge Economy and the Cultural Industries: Employment Trends and Prospects for Economic Development, Presentation to the Economy of the Arts Conference, Dublin, 1-3 December 1994.

O'Connor, J. and D. Wynne (ed.) (1996), From the Margins to the Centre: Cultural Production and Consumption in the Post-Industrial City, Aldershot, Arena. 
Pais, J. Machado (org.) (1994), Práticas Culturais dos Lisboetas: Resultados do Inquérito Realizado em 1994 aos Habitantes da Grande Lisboa, Lisboa, ICS-UL.

Pronovost, G. (1996), Médias et Pratiques Culturelles, Grenoble, Presses universitaires de Grenoble.

Santos, Maria de L. Lima dos (org.) (1998), As Políticas Culturais em Portugal, Lisboa, Observatório das Actividades Culturais.

Santos, H. et al. (1999), Consumos Culturais em Cinco Cidades: Aveiro, Braga, Coimbra, Guimarães e Porto, Coimbra, Oficina do CES, 146.

Scott, A. J. (1996), The Cultural Economy of Cities, Working Papers on Producer Services, 35, University of Bristol and Service Sector Research Unit The University of Birmingham, August 1996.

Scott, A. J. (1997), “De la Silicon Valley à Hollywood: croissance et développement de l'industrie multimedia en Californie", Espace et Sociétés, 88/89, Paris, L'Harmattan.

Shapiro, D., N. Abercombie, S. Lash and C. Lury (1992), "Flexible specialization in the culture industries", in H. Ernste, and V. Meier (Eds.), Regional Development and Contemporary Industrial Response: Extending Flexible Specialization, London / New York, Belhaven, pp. 179-194.

Teixeira, J. M. Lopes (2000), A Cidade e a Cultura: Um Estudo Sobre Práticas Culturais Urbanas, Porto, Afrontamento.

Vogel, H. L. (1997), Entertainment Industry Economics: A Guide For Financial Analysis, Cambridge, Cambridge University Press, $4^{\text {th }}$ ed.

Wynne, D. (ed.) (1992), The Culture Industry, Swindon, Avebury.

Pedro Costa. Docente do ISCTE. Investigador do DINÂMIA e do CIRIUS ISEG, UTL. Contacto: ISCTE, Departamento de Economia, Av. das Forças Armadas, 1649-026 Lisboa. E-mail: pedro.costa@iscte.pt. 